\title{
Objectively measured compliance during early orthodontic treatment: Do treatment needs have an impact?
}

\author{
Michał Sarull ${ }^{A-F}$, Beata Kawala ${ }^{\mathrm{E}, \mathrm{F}}$, Anna Kozanecka ${ }^{\mathrm{C}, \mathrm{F}}$, Jan Łyczek $^{\mathrm{B}}$, Joanna Antoszewska-Smith ${ }^{\mathrm{A}, \mathrm{C}, \mathrm{E}, \mathrm{F}}$ \\ Department of Maxillofacial Orthopedics and Orthodontics, Wroclaw Medical University, Poland \\ A - research concept and design; $B$ - collection and/or assembly of data; $C$ - data analysis and interpretation; \\ $D$ - writing the article; $E$ - critical revision of the article; $F$ - final approval of article
}

\section{Address for correspondence \\ Michał Sarul}

E-mail:michal.sarul@gmail.com

\section{Funding sources}

The study was funded from the grand awarded

by Wroclaw Medical University

\section{Conflict of interest}

none declared

Received on November 5, 2015

Revised on December 10, 2015

Accepted on March 8, 2016

\begin{abstract}
Background. Objective assessment of daily wear time of removable appliances is possible, so the next step is to ascertain whether the severity of malocclusion influences patients' compliance. This could help resolve the controversy over the question of whether removable appliance therapy truly works.

Objectives. The aim of the study was to investigate whether the patient's orthodontic treatment needs affect the cooperation between the patient and the doctor, and to find a correlation that could affect recommendations for orthodontic treatment.
\end{abstract}

Material and methods. The study involved 58 patients ( 29 boys, 29 girls) aged $9-12$ years, who qualified for treatment with removable appliances equipped with a sensor system. The patients were divided into four groups according to their Index of Orthodontic Treatment Need dental health component scores. Over a 9-month period, data stored in the sensors were compared with the recommended daily wear time (DWT) of the appliances, and a statistical analysis was conducted.

Results. DWT differed considerably in all the groups. Statistically significant differences in the mean DWT values occurred only when extreme values of the IOTN DHC were compared.

Conclusions. The degree of patient compliance depends to a small extent on the severity of malocclusion. Patients with mild malocclusion will probably be less likely to cooperate. Among patients with severe malocclusion, compliance may be unpredictable. Patient compliance is an important background factor that can explain a lot of the controversy over the effectiveness of treatment with removable appliances.

Key words: Index of Orthodontic Treatment Need, orthodontics, orthodontic removable appliances, patient compliance

DOI

10.17219/acem/62107

Copyright

Copyright by Author(s)

This is an article distributed under the terms of the

Creative Commons Attribution Non-Commercial License

(http://creativecommons.org/licenses/by-nc-nd/4.0/) 
When starting orthodontic treatment, the "golden rules" formulated by Proffit et al. should always be borne in mind: (i) Each treatment should be aimed at improving the patient's quality of life, and (ii) the treatment should be provided for the patient, and not carried out on him. ${ }^{1}$

Since esthetics are one of the major reasons patients seek orthodontic treatment, the patient's feelings, not the orthodontist's, should be the most important point of reference in orthodontic practice committed to creating beautiful smiles. ${ }^{2}$ On the other hand, however, the existence of an objective point of reference in terms of facial and smile esthetics can be very helpful when carrying out orthodontic treatment, conducting research and formulating individual treatment plans. ${ }^{3}$ Taking all this into account, the orthodontist must always bear in mind that even if his or her rules, plans and treatment objectives are based on accurate, numerical parameters used to assess individual dentofacial features, the results of such analyses may not be aligned with the patient's sense of self-esteem. The Index of Orthodontic Treatment Need (IOTN) is one of the measurements that takes into account not only measurable classifications of malocclusion, but also a hierarchical evaluation of dental esthetics. This index may prove to be a particularly useful tool, allowing orthodontists to make treatment decisions that take into account the most important factor for the patient, namely impairment of oral esthetics. ${ }^{4}$ Since this factor is one of the main reasons patients decide to endure the burden of orthodontic treatment, the next logical step is to ask how the patient's critical self-assessment of his or her smile affects his or her behavior and attitude during the treatment, and whether it corresponds to the objective, parametric orthodontist's assessment. This seems particularly important if removable orthodontic appliances are to be used, in which case an objective, parametric assessment of the patient's malocclusion affects his or her motivation and level of compliance.

Removable appliances have been used in orthodontic treatment for many decades. As bonded attachments are presently in wide use, removable appliances may seem a relic of a bygone era, yet they have their merits. They are easy to manufacture and use, they show resistance to damage and reduce the risk of iatrogenic decay developing during orthodontic treatment. Most of all, they are inexpensive and perfectly suitable for solving many problems in early and interceptive orthodontic treatment, and therefore in the general treatment of children and young people. ${ }^{5}$ The biggest drawback with the use of removable appliances is that it is very difficult to predict and monitor patient compliance with the treatment, and removable appliances must be worn as advised by the orthodontist to be effective. Until recently, fully objective measurement of patient compliance was practically impossible. This affected not only clinical procedures, but also the credibility of various studies related to this kind of therapy. Patient compliance was a factor that, if ignored, could have a sub- stantial impact on studies on the effectiveness of removable appliances, thereby affecting recommendations on treatment strategies issued on the basis of these studies. ${ }^{6}$ It was not until recently that this problem was solved, as the emergence of electronic systems for monitoring patient compliance has finally helped to assess real, daily appliance-wear time (DWT). TheraMon ${ }^{\circledR}$ (MC Technology $\mathrm{GmbH}$, Hargelsberg, Austria) is one such system. Its efficacy has been confirmed in clinical studies. ${ }^{6}$

TheraMon ${ }^{\circledR}$ consists of: (a) sensors which read and save temperature values to an accuracy of $0.1^{\circ} \mathrm{C}$ every $15 \mathrm{~min}$; (b) a docking station which allows the data stored on the sensors to be read; and (c) software that not only makes analysis, visualization and interpretation of data possible, but also identifies attempts at manual adjustment/fraud.

As the problem of objective monitoring of patient compliance with treatment with removable appliances has now been overcome, the time has come to answer a key question, namely: Do the orthodontic treatment needs of the patient, defined before the treatment with the use of IOTN, affect the cooperation between the patient and the doctor? The purpose of this research was to find any correlation that could significantly affect recommendations for orthodontic treatment, especially those that are statefunded or covered by other insurance systems.

\section{Material and methods}

The study group consisted of 58 patients (29 boys and 29 girls) aged 9-12 years. The minimum sample size was established by determining the strength of the statistical t-test used to assess the statistical significance of the Pearson correlation coefficient with a properly adjusted (smaller) number of cases. It has been demonstrated that a sample size of $\mathrm{n}=58$ provides the statistical power of 0.8 .

The patients were diagnosed with at least one of the following malocclusions:

a) increased overjet,

b) reverse overjet without speech or functional disorders,

c) crossbite,

d) contact point displacements,

e) open bite,

f) increased overbite,

g) teeth that do not all fit on a line of occlusion,

h) hypodontia,

i) disturbance in tooth eruption/tooth impaction, and/or

j) a partially erupted tooth, inclined and stopped by adjacent teeth.

The orthodontic treatment needs were assessed in all the patients as part of the diagnostic activities, prior to the formulation of a treatment plan. The dental health component (DHC) of the IOTN was assessed for all the patients by the same previously calibrated orthodontist (AK). On this basis the patients were divided as follows: 
Group 1: IOTN DHC = 2 (14 individuals), Group 2: IOTN DHC = 3 (13 individuals), Group 3: IOTN DHC = 4 (16 individuals), Group 4: IOTN DHC $=5$ (15 individuals).

The patients were qualified for treatment with Schwarz or Twin Block appliances equipped with TheraMon ${ }^{\circledR}$ sensors.

Before the treatment began, all the patients and their carers were informed of the purpose of the study and signed informed consent to participate in the research, which was approved by the Wroclaw Medical University Bioethics Committee (No. KB - 322/2014).

Once removable appliances were provided to the patients, both they and their parents/carers were informed that the appliances should be worn at night for at least $8-10 \mathrm{~h}$ and during the day for at least $2-4 \mathrm{~h}$, so that the DWT was at least $10-14 \mathrm{~h}$.

Over the next nine months, the data stored on each of the sensors were read out every 4-6 weeks during patient visits, objectively measuring daily appliance-wear time. All the data were further subjected to statistical analysis. The calculations were carried out using STATISTICA 12.0 software (StatSoft Inc., Tulsa, USA), using tests relevant to the distribution of variables. Significance was established at a p level less than 0.05 .

\section{Results}

DWT differed considerably in all the groups (Fig. 1). Surprisingly, the lowest DWT value was observed in the patients in Group 3 (0.97 h/day), while the highest DWT value, as expected, was registered in Group 4 (21.93 h/ day). The DWT values, along with descriptive statistics and the Shapiro-Wilk normality test results were used to show that the DWT variable is normally distributed in all

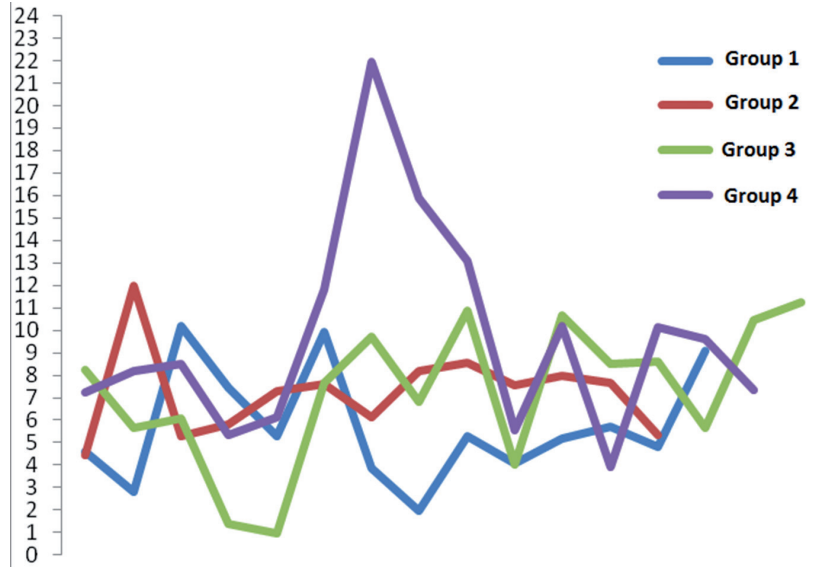

Fig. 1. Daily wear time values (0-24 h/day)

groups, are summarized in Table 1. Statistical power was also analyzed, because if the assumption about normality of distribution is correct, the power of the rank-based tests is lower than that of Student's t-test based on this assumption. If the sample size is equal to $\mathrm{n}$, the statistical power of Spearman's rank correlation coefficient may be almost the same as the statistical power of Pearson's correlation coefficient (also known as Pearson's r) for a sample of $9 / \pi 2$ $\mathrm{N}$ (approximately $0.912 \mathrm{n}$ ) cases. ${ }^{7}$ For practical purposes, the statistical power of Spearman's rank correlation coefficient was analyzed by computing the power of Student's t-test used to assess the statistical significance of Pearson's correlation coefficient with reference to an adequately adjusted (smaller) number of cases; it was found that the sample size $n=58$ provides statistical power of 0.8 . The results of the statistical analysis of covariance between the DWT and the dental health component of the IOTN are presented in Table 2. The value of Spearman's rank coefficient $(r=0.370)$ indicates a poor monotonic relationship

Table 1. Daily appliance wear time (DWT) in each group, along with descriptive statistics and the results of the Shapiro-Wilk test

\begin{tabular}{|c|c|c|c|c|c|c|c|c|}
\hline \multirow[b]{2}{*}{ Group number } & \multicolumn{6}{|c|}{ Daily Wear Time (DWT) } & \multicolumn{2}{|c|}{ The Shapiro-Wilk test } \\
\hline & $\begin{array}{l}\text { number of } \\
\text { patients }(n)\end{array}$ & mean & $\mathrm{SD}$ & SE & \multicolumn{2}{|c|}{$95 \% \mathrm{Cl}$} & W & $p$-value \\
\hline $\begin{array}{l}\text { Group } 1 \\
(\text { IOTN DHC = 2) }\end{array}$ & 14 & 5.73 & 2.53 & 0.68 & 4.27 & 7.19 & 0.918 & 0.204 \\
\hline $\begin{array}{l}\text { Group } 2 \\
(\text { IOTN DHC = 3) }\end{array}$ & 13 & 7.46 & 2.07 & 0.66 & 5.98 & 8.94 & 0.919 & 0.351 \\
\hline $\begin{array}{l}\text { Group } 3 \\
(\text { IOTN DHC = 4) }\end{array}$ & 16 & 7.29 & 3.19 & 0.80 & 5.59 & 8.99 & 0.924 & 0.195 \\
\hline $\begin{array}{l}\text { Group } 4 \\
(\text { IOTN DHC = 5) }\end{array}$ & 15 & 9.66 & 4.64 & 1.20 & 7.09 & 12.2 & 0.893 & 0.073 \\
\hline All groups & 58 & 7.57 & 3.57 & 0.48 & 6.60 & 8.54 & & \\
\hline
\end{tabular}

Table 2. The results of the statistical analysis of covariance between DWT and the IOTN Dental Health Component

\begin{tabular}{|l|c|c|c|c|}
\hline Variables & $\begin{array}{c}\text { Number of } \\
\text { patients }(\mathrm{n})\end{array}$ & $\begin{array}{c}\text { Spearman's rank } \\
\text { correlation coefficient }\end{array}$ & $\mathrm{t}(\mathrm{N}$-2) & p-value \\
\hline DWT and the IOTN DHC & 58 & 0.370 & 2.903 & 0.005 \\
\hline
\end{tabular}


Table 3. The results of the statistical analysis of DWT differentiation in each group

\begin{tabular}{|c|c|c|c|c|c|}
\multirow{2}{*}{$\mathrm{k}$} & $\begin{array}{c}\text { Number of } \\
\text { patients }(\mathrm{n})\end{array}$ & \multicolumn{2}{|c|}{ The Brown-Forsythe test } & \multicolumn{2}{|c|}{ Analysis of variance (ANOVA) } \\
\cline { 3 - 6 } & 58 & $\mathrm{~F}(\mathrm{k}-1, \mathrm{n}-\mathrm{k})$ & $\mathrm{p}$-value & $\mathrm{F}(\mathrm{k}-1, \mathrm{n}-\mathrm{k})$ & $\mathrm{p}$-value \\
\hline 4 & 1.549 & 0.213 & 3.363 & 0.026 \\
\hline
\end{tabular}

Table 4. The results of the post hoc Tukey Honest Significant Differences (HSD) test: An analysis of pairwise comparisons

\begin{tabular}{|l|c|c|c|}
\multirow{2}{*}{ Group number } & \multicolumn{3}{|c|}{ p-value } \\
\cline { 2 - 4 } & group 3 & group 4 & group 5 \\
\hline Group 2 & 0.661 & 0.615 & 0.017 \\
Group 3 & & 1.000 & 0.468 \\
Group 4 & & & 0.229 \\
\hline
\end{tabular}

between these variables. The positive coefficient value suggests that a higher IOTN DHC value is usually associated with longer appliance-wear time, but this relationship is not very strong.

In order to statistically analyze the DWT differentiation, the Brown-Forsythe test was used for particular groups. That test did not show any significance; therefore, a parametric analysis of variance (ANOVA) was performed, which did show a significant difference (Table 3). A post hoc Tukey Honest Significant Differences (HSD) test for unequal frequencies performed at the end demonstrated that statistically significant differences in the DWT mean values occurred only when extreme values of the IOTN DHC were compared - i.e. in Groups 1 and 4, where the DWT mean values were $5.73 \mathrm{~h} /$ day and $9.66 \mathrm{~h} /$ day, respectively (Table 4).

\section{Discussion}

Removable appliances have been used in orthodontic treatment for decades. They have both opponents and supporters. It seems that one of the main drawbacks is the necessity to wear the appliances for sufficiently long periods of time a day. Some authors have assumed that patient compliance with this requirement may depend on the level of the patient's (and his or her carers') motivation to undergo orthodontic therapy; this in turn should depend on the severity of the malocclusion that is the reason for seeking treatment. Logically, the patients with severe malocclusion should follow the doctor's instructions, which - thanks to sensors placed in functional orthodontic appliances - can now be objectively verified.

There are several main factors influencing the decision to undergo orthodontic treatment. They include (a) the relationship between malocclusion and a higher incidence of tooth decay and periodontal disease, (b) the prevalence of stomatognathic system disorders resulting from occlusal problems, and (c) the psychosocial impairment caused by malocclusion.
Studies show that the relationship between malocclusion and the prevalence of chewing impairment or TMJ disorders is weak, inconclusive or non-existent. A study conducted by Helm and Petersen suggested that malocclusion affects the prevalence of oral diseases much less than oral hygiene, which depends only on the patient. ${ }^{8-10}$ Moreover, studies conducted by Sádovský and BeGole and by Polson show that the prevalence of malocclusion only marginally affects the development of periodontal disease. ${ }^{11,12}$ It therefore seems that malocclusion has a greater impact on the patient's psychological well-being and social functioning. As Soares et al. wrote, "people usually seek [orthodontic treatment for malocclusion] to improve their esthetic appearance because other people's opinions directly or indirectly affect their self-esteem and how they perceive their own appearance".13-17

Nevertheless, scientific evidence, backed by a reliable statistical analysis, is something very different from patients' (and/or their carers) awareness and the resulting motivation (or lack thereof) to undergo treatment and follow their orthodontists' instructions. In a sense, the present study could be an attempt to argue with Proffit et al., who claimed that the main reason for seeking orthodontic treatment is psychosocial maladjustment caused by malocclusion. ${ }^{18}$ The present authors have not examined the relationship between appliance wear time (and thus motivation) and the patients' self-assessment of their facial esthetics. However, an attempt has been made to objectively assess the patients' orthodontic treatment needs and to link them to their motivation. As already noted, the results are not conclusive, but the observation can be made that the more severe the malocclusion, the higher the patient's motivation to put a lot of effort into orthodontic treatment. There is a statistically significant relationship between these two variables, which is consistent with the opinion of Proffit et al. ${ }^{1}$ This statistical significance only becomes noticeable, however, when patients with severe malocclusion are compared with patients with mild malocclusion. In other cases, the results are not statistically significant. It must also be noted that the observed correlation is not very strong (0.37). Perhaps this means that patients value their own self-assessment of their malocclusion more than an objective clinical assessment; furthermore, other factors cannot be excluded.

From a clinical point of view, the direct correlation between the severity of malocclusions and patient compliance is not the only factor of importance; the standard deviation of daily wear time results also has an impact. Closer analysis shows that the higher the value of the IOTN DHC parameter, the higher the standard deviation 
of the daily wear time. It is therefore important to think carefully about how to interpret these results. Inasmuch as the level of patient compliance is low in cases of mild malocclusion, it is also more predictable than in patients with severe malocclusion ( $\mathrm{SD}=2.53)$. On the average, the latter group cooperates much better, but the compliance of any individual in the group is definitely less predictable than individuals with mild malocclusion ( $S D=4.64)$. These findings may help to partially explain the results obtained by some authors, which show considerable differences in the skeletal changes that occur during orthopedic treatment. ${ }^{19-21}$ Even if these changes are beneficial, substantial standard deviation of the results causes them to lose significance in the statistical analysis in comparison to an untreated control group. Unfortunately, the present study has confirmed this mechanism, showing that the greater the severity of malocclusion, the bigger the difference in the degree to which the patients follow a treatment regimen, leaving orthodontists insufficient control over patient compliance.

\section{Conclusions}

The degree of patient compliance depends to a small extent on the severity of malocclusion measured by the IOTN. When planning early treatment with removable appliances, it can be assumed that patients with mild malocclusion will be less likely to cooperate, which should influence care provider's decisions to limit public funds spent on the treatment of such disorders. Unfortunately, among patients suffering from severe malocclusion compliance is unpredictable, which means the treatment should be carefully and objectively monitored, and discontinued when the doctor's recommendations are not followed. Since the severity of malocclusion is a weak predictor of patient compliance, research should continue to search for other prognostic factors. The results of the present study show that patient compliance is an important background factor, which may explain a great deal of the controversy over the effectiveness of functional treatment.

\section{References}

1. Proffit WR, Fields HW, Sarver DM. Contemporary orthodontics. St. Louis, Mo: Mosby Elsevier; 2007: Chap.6.

2. Peck H, Peck S. A concept of facial esthetics. Angle Orthod. 1970;40:284-317.

3. Kiekens RMA, Maltha JC, Hof MA, Kuijpers-Jagtman AM. Objective measures as indicators for facial esthetics in white adolescents. Angle Orthod. 2006;76;551-556.

4. Shaw WC, Richmond S, O'Brien KD. The use of occlusal indices: A European perspective. Am J Orthod Dentofacial Orthop. 1995;107:1-10.

5. Nimri K, Richardson A. Applicability of interceptive orthodontics in the community. British J Orthod. 1997;24:223-228.

6. Schott TC, Goz G. Young patients attitudes' toward removable appliance wear times, wear-time instructions and electronic weartime measurements - results of a questionnaire study. J Orofac Orthop. 2010;71:108-116.

7. Hotelling $\mathrm{H}$, Pabst MR. Rank correlation and tests of significance involving no assumption of normality. Ann Math Stat. 1936;7:29-43.

8. Feine JS, Maskawi K, de Grandmont P, Donohue WB, Tanguay R, Lund JP. Within-subject comparisons of implant-supported mandibular prostheses: Evaluation of masticatory function. J Dent Res. 1994;73:1646-1656.

9. McNamara JA, Seligman DA, Okeson JP. Occlusion, orthodontic treatment and temporomandibular disorders. J Orofacial Pain. 1995;9:73-90.

10. Proffit WR, Fields HW, Sarver DM. Contemporary orthodontics. St. Louis, Mo: Mosby Elsevier; 2007:Chap. 2.

11. Sadovsky C, BeGole EA. Long-term effects of orthodontic treatment on the periodontal health. Am J Orthod. 1981;80:156-172.

12. Polson AM. Long-term effect of orthodontic treatment on the periodontium. McNamara JA, Ribbens KA, eds. Malocclusion and the periodontium. AnnArbor, Mich: The University of Michigan Press; 1987.

13. Shaw WC. The influence of children's dentofacial appearance on their social attractiveness as judged by peers and lay adults. Am J Orthod. 1981;79:399-415.

14. Mandall NA, McCord JF, Blinkhorn AS, Worthington HV, O'Brien KD. Perceived aesthetic impact of malocclusion and oral self-perceptions in 14-15-year-old Asian and Caucasian children in greater Manchester. Eur J Orthop. 2000;22:175-183.

15. Shaw WC, Rees G, Dawe M, Charles CR. The influence of dentofacial appearance on the social attractiveness of young adults. Am J Orthod. 1985;87:21-26.

16. Cons NC, Jenny J, Khout FJ. Perceptions of occlusal conditions in Australia, the German Democratic Republic and the United States. Int Dent J. 1983;33:200-206.

17. Farrow $A L$, Zarinnia $K$, Khosrow A. Bimaxillary protrusion in black Americans - an esthetic evaluation and the treatment considerations. Am J Orthod Dentofac Orthop. 1993;104:240-250.

18. Proffit WR, Fields HW, Sarver DM. Contemporary orthodontics. St. Louis, Mo: Mosby Elsevier; 2007:Chap. 8.

19. Chen JY, Will LA, Niederman R. Analysis of efficacy of functional appliances on mandibular growth. Am J Orthod Dentofacial Orthop. 2002;122:470-476.

20. Keeling SD, Wheeler TT, King GJ, et al. Anteroposterior skeletal and dental changes after early Class II treatment with bionators and headgear. Am J Orthod Dentofacial Orthop. 1998;113:40-50.

21. Tulloch JFC, Proffit WR, Phillips C. Outcomes in a 2-phase randomized clinical trial of early Class II treatment. Am J Orthod Dentofacial Orthop. 2004;125:657-667. 